\title{
High rates of undiagnosed and untreated osteoporosis in postmenopausal women receiving medical services in the area of Upper Silesia
}

\author{
Marcin Hachuła ${ }^{1}$, Barbara Pietrzyk², Wojciech Gruszka², Ida Cedrych ${ }^{3}$, Jerzy Chudek ${ }^{2,3}$ \\ ${ }^{1}$ Student Scientific Society, Department of Pathophysiology, Faculty of Medical Sciences in Katowice, Medical University of Silesia \\ in Katowice, Poland \\ ${ }^{2}$ Pathophysiology Unit, Department of Pathophysiology, Faculty of Medical Sciences in Katowice, Medical University of Silesia \\ in Katowice, Poland \\ ${ }^{3}$ Department of Internal Medicine and Oncological Chemotherapy, Faculty of Medical Sciences in Katowice, Medical University \\ of Silesia in Katowice, Poland
}

\section{Abstract}

Introduction: High social cost and high risk of disability make postmenopausal osteoporosis one of major public health problem in the $21^{\text {st }}$ century. The aim of this study was to assess frequency of undiagnosed and untreated osteoporosis in postmenopausal women in the Upper Silesia Region of Poland. Additionally, we compare estimation of the 10-year probability of major osteoporotic fractures (MOF) and hip fractures (HF) based on fracture risk assessment tool (FRAX) with and without bone mineral density (BMD).

Material and methods: The survey included 450 postmenopausal women (age $65 \pm 11$ years). A detailed questionnaire included demographic and anthropometric data, comorbidity, history of previous low-energy fractures, family medical history, and treatment for osteoporosis. The FRAX calculator was used to estimate the risk of MOF and HF.

Results: Osteoporosis was previously diagnosed in $23.7 \%$ women. Of those $70.2 \%$ were receiving vitamin D, $27 \%$ calcium preparations, $33 \%$ bisphosphonates, and $22 \%$ were untreated. Only $42.2 \%$ women with previous fractures had been diagnosed with osteoporosis and $42.8 \%$ received any treatment. $12.5 \%$ women with FRAX$\mathrm{BMD} \geq 10 \%$ had no risk factors of osteoporosis and $<10 \%$ risk of MOF and HF in FRAX without BMD.

Conclusions: Osteoporosis often remains undiagnosed and untreated in postmenopausal women. There is a great need to popularize FRAX without BMD calculator among physicians, especially GPs, as the risk calculation justify the implementation of antiosteoporotic therapy. Women with burden of risk factors of fractures and borderline FRAX without BMD values, should be referred to a densitometry examination, as having greater risk of fracture than shown by FRAX without BMD.

Key words: osteoporosis, postmenopausal women, undiagnosed osteoporosis, untreated osteoporosis, FRAX calculator.

\section{Introduction}

Osteoporosis is a metabolic bone disease, characterized by a decrease in mineral bone density (BMD) with increased risk of low energy fractures [1]. High personal and social cost make postmenopausal osteoporosis (PMO) one of a major public health problem in the $21^{\text {st }}$ century. Overall 22 million women (21\% of aged $50-84$ years) across the countries of European Union have PMO $[2,3]$. Typical sites for osteoporotic fracture are distal forearm (Colles' fracture), upper part of the femur and compression fractures of the spine [4]. Especially hip fractures (HF) are the cause of extended, often incomplete recovery, and $8 \%$ to $36 \%$ one-year mortality [5].
Approximately $20 \%$ patients require permanent nursing care or institutionalization [6]. WHO definition of osteoporosis is based on the T-score for bone mineral density (BMD) assessed by dual-energy X-ray absorptiometry (DXA) of the femoral neck or spine and is defined as a value for BMD -2.5 standard deviation (SD) or less [7]. However, $70 \%$ of fractures occur in person with lower BMD. National Bone Health Alliance (NBHA) extended the recognition criteria to: low energy HF without a decrease in BMD value; low-trauma major osteoporotic fracture (MOF) and osteopenia or osteoporosis at densitometry examination; fracture risk assessment tool (FRAX) with BMD (FRAX-BMD) 
$>10 \%$ (for Polish population) with or without low-energy fractures $[8,9]$. FRAX was developed to assess 10-year probability of MOF and the 10-year risk of HF, based on clinical risk factors, exclusively (FRAX without BMD). The calculator was design as a simple tool to identify patients with risk of fractures, easily applicable by general practitioners [10].

Despite the efforts of popularization of FRAX without BMD, there is a large number of undiagnosed women without history of osteoporotic fractures, that could be eligible based on FRAX values or BMD assessment. A retrospective study performed in the USA among women that experienced HF, showed that only $13-15 \%$ of them were previously diagnosed with osteoporosis $[11,12]$. Screening test performed in Switzerland among patients referred to the geriatric post-acute rehabilitation unit revealed that $71.5 \%$ of women had undiagnosed osteoporosis [13]. The problem of undiagnosed osteoporosis in Poland has not been studied, yet.

In addition to undiagnosed PMO, there is a great number of patients diagnosed with osteoporosis who have not received treatment, worldwide. American cohort study revealed that only $30.4 \%$ patients after low-energy fracture received anti-osteoporotic therapy [14]. In 2010 in Europe, only 43\% of women with PMO were treated, with significant variation in the frequency between countries. As much as $75 \%$ of osteoporotic women were receiving appropriate therapy in Spain, while in Bulgaria about 95\% patients remained untreated [15]. Treatment gap in Poland was estimated at $78 \%$ [16]. However, according to National Health Fund register, there are 2.25 million women with low-energy fracture, while only about 200 thousands people receive bisphosphonates (or denosumab)-based pharmacological treatment for osteoporosis (National Sales Data). That means that less than $10 \%$ have an adequate therapy. The reason of low adherence to the therapy could be explained by frequently asymptomatic course of PMO, delayed effects of the treatment, complicated schedule of oral bisphosphonate administration, and polypharmacy related to comorbidities in older women affected by the fractures [17].

The aim of this study was to assess scale of undiagnosed and untreated osteoporosis in the postmenopausal women in the Upper Silesia Region of Poland. Additionally, we compare estimation of the 10-year probability of MOF and HF based on FRAX with and without BMD.

\section{Material and methods}

Four-hundred-fifty postmenopausal women have been enrolled to the survey. It was carried out in primary health care centers (GP's): NZOZ "Przychodnia" in Chorzów, NZOZ Euromed-M in Mysłowice, SPZOZ in Imielin, Department of Internal Medicine in Clin- ical Hospital No. 7 of the Silesian Medical University, SPZOZ Railway Hospital in Katowice, Municipal Hospitals Complex in Chorzow, SPZOZ Multispecialty Hospital in Jaworzno, SPZOZ Hospital No. 2 in Mysłowice, and densitometry centers localized in NZOZ ZBM "Zdrowie" in Bytom and Pro \& Diagnostic in Sosnowiec, between January 2017 and March 2018. Physicians and medicine students (co-author of this paper) created for the purpose of this the study questionnaire, based on interview with the patient during a routine visit, after receiving a consent to participate in this survey. The study was performed anonymously, without collection patients' personal data. Premenopausal women were excluded. The study was conducted as a survey that did not fulfill the medical experiment criteria therefore did not require Bioethical Committee approval.

\section{Study questionnaire}

The questionnaire was based on the risk factors included in the FRAX calculator and contained the following: demographic data (age, gender); anthropometric data (body mass, height); concomitant diseases: hyperthyroidism, hypothyroidism or premature menopause ( $<45$ years), type 1 or type 2 diabetes, bronchial asthma, rheumatic diseases, cancers, chronic colitis; family history (family HFs and/or other low-energy fractures); medicines taken (especially oral glucocorticoids - currently or previously for more than 3 months), history of fractures with their locations; alcohol consumption (3 or more units/day); smoking, as well as: occurrence of falls, dizziness, difficulty in moving, vision disorders, supplementation with vitamin D and calcium. The duration and composition of the current anti-osteoporosis therapy, and the utilization of specialist medical care in patients diagnosed with osteoporosis. Outpatients of the densitometry center, at the first visit had been carried out densitometry of the hip. The DXA examinations have been carried out using GE Lunar Prodigy Primo densitometers.

\section{Ten years risk for osteoporotic fractures}

The FRAX calculator has been used for estimation of the average 10 years risk for MOF. In addition, in those with measured BMD of the hip, a 10 years risk for HF including HF T-score was calculated. The analysis includes comparison of both FRAX scores values (FRAX-BMD and FRAX without BMD).

\section{Data analysis}

Study group was divided into subgroups depending on the previous diagnosis of osteoporosis and history of low energy fractures. 


\section{Statistical analysis}

Statistical analysis was performed with Statistica 12.0 software (Cracow, Poland). The results were presented as: mean \pm standard deviation or the percentages for the data in nominal and ordinal scale. Normality of data distribution was assessed with the Shapiro-Wilk test. Comparison of variables in nominal and ordinal scale was done with the $\chi^{2}$ test. In order to compare analyzed variables among groups the $t$-test for independent means or the $U$ Mann-Whitney test (in the case of non-compliance with the condition of $t$-test) were used. In order to compare variables among groups with different T-score values, analysis of variances with the contrast analysis was performed. Homogeneity of variance was assessed with the Levene's test. In the case of non-compliance with the condition of parametric ANOVA test, nonparametric equivalent - ANOVA Kruskal-Wallis test was used. The results were considered as statistically significant with a $p$-value of less than 0.05 .

\section{Results}

\section{Study group characteristics}

The study group consisted of 450 postmenopausal women (mean age of $65 \pm 11$ years), including 53 with a premature menopause (in age $\leq 45$ years). There were 186 overweight (BMI 25-29.9) and 115 obese (BMI $\geq 30)$ women. Almost every fourth women (23\%) reported that parents have been diagnosed with osteoporosis. The concomitant diseases included: hypertension (51.5\%), type 1 or 2 diabetes (38.4\%; HbA1c $-7.8 \pm 0.9 \%$ ), thyroid diseases (10\%), rheumatoid arthritis (RA) (8.4\%) and chronic colitis (4\%). Falls during a period of last year were reported by $41.7 \%$. Fatigue was declared by $27.3 \%$ women. There were $34.9 \%$ alcohol consumers and $14.5 \%$ active smokers. In addition, $11.3 \%$ patients $(n=51)$ were currently treated with glucocorticoids.

Mean FRAX without BMD for MOF was $8.8 \pm 7.3 \%$ and FRAX without BMD for the HF was $3.4 \pm 4.9 \%$ (Table 1). One-hundred-thirteen of study subjects had a densitometry examination. In this subgroup calculated average 10-year risk for MOF was $14.0 \pm 9.6$ for the FRAX-BMD and $11.1 \pm 8.8 \%$ for the FRAX without BMD. For HF it was $6.2 \pm 6.1 \%$ for FRAX-BMD and 4.6 $\pm 5.8 \%$ for FRAX without BMD. Mean BMD T-score value was $-2.48 \pm 0.75$ (range: -3.95 to -0.44 ), and the mean $\mathrm{BMI}$ was $26.6 \pm 3.7$. Every 10 -year increase in age was increasing the risk of fracture by $3.2 \%$ for FRAX-BMD and $6.6 \%$ for FRAX without BMD.

\section{Low energy fractures in the study group}

There were 166 women with previous osteoporotic fractures and 284 women without fractures in the past. Only 70 women with previous fractures (42.2\%) had been diagnosed with osteoporosis and 30 (42.8\%) of them were treated. The subgroup of women with fractures was significantly older, had lower BMI, higher frequency of diabetes, dizziness and falls during the last year, were more often treated with glucocorticoids and vitamin D, as well as had family history of osteoporosis, than those without fractures.

There were no significant differences in terms of frequency of smoking, declared alcohol consumption, the occurrence of hypertension, RA, thyroid diseases, depression and the age of menopause between women with and without fractures (Table 2).

Patients with T-score $<-2.5$ with bone fractures had significantly higher $(p<0.001)$ FRAX-BMD MOF, FRAXBMD HF, FRAX without BMD MOF and FRAX without BMD HF than people with T-score $<-2.5$ without bone fractures and women with T-score $>-2.5$ (Table 3 ).

\section{Patients with diagnosed osteoporosis}

One-hundred-eleven women (23.7\%) had been diagnosed with PMO (mean age $71.4 \pm 9.2$ years). Of those 70 women $(63 \%)$ had a history of low energy fractures (52\% forearm, $28 \%$ proximal end of femur, $20 \%$ vertebral collapse), $63 \%$ over the period of last year experienced a fall, and $57 \%$ reported decrease in height by an average of $1.8 \pm 2.5 \mathrm{~cm}$. Glucocorticoids were currently prescribed to $16.2 \%$. Women diagnosed with osteoporosis were significantly older, more often reported dizziness, and had type 2 diabetes, had a history of osteoporotic fractures in the family as compared to women without osteoporosis (Table 1).

Vitamin D supplementation was declared by $70.2 \%$ of patients, but only in one-third, it was prescribed by a doctor. In addition, $27 \%$ of them has been taking calcium containing drugs and only $33 \%$ of them has been using bisphosphonates (most often alendronate - 51\%, ibandronate $-25 \%$, pamidronate $-16 \%$ and zoledronic acid $-8 \%$ ). Patients were frequently managed by orthopedists (56\%) and rheumatologists (48\%).

\section{Undiagnosed patients}

Diagnostic criteria based on the T-Score BMD and interview data allowed the diagnosis of PMO in 103 women. However, only $41 \%(n=42)$ of women declared previously diagnosed osteoporosis.

The lack of diagnosis of osteoporosis was declared by 44 out of 61 women with a BMD T-score $\leq-2.5$; 7 out of 26 with HF; 5 out of 6 with a history of low-energy fracture with + T-score $\geq-1$; and 5 women with FRAX-BMD $\geq 10 \%$ in the absence of fractures and BMD T-score $>-2.5$ (Fig. 1).

The study showed that 25 (24\%) women were not diagnosed with osteoporosis despite being managed by orthopedists and 19 (18\%) by rheumatologists. 
Table 1 . Study group characteristics $(n=450)$ and comparison between women diagnosed $(n=111)$ and undiagnosed with osteoporosis $(n=339)$

\begin{tabular}{|c|c|c|c|c|}
\hline \multirow[t]{2}{*}{ Characteristics } & \multicolumn{4}{|c|}{ Diagnosed with osteoporosis } \\
\hline & $\begin{array}{l}\text { All subjects } \\
(n=450)\end{array}$ & $\begin{array}{c}\text { Yes } \\
(n=111)\end{array}$ & $\begin{array}{c}\text { No } \\
(n=339)\end{array}$ & $\begin{array}{c}\text { Statistical } \\
\text { significance }(p)\end{array}$ \\
\hline Age, years & $65.0 \pm 11.0$ & $71.4 \pm 9.2$ & $63.2 \pm 10.7$ & $<0.001$ \\
\hline$<50, n(\%)$ & $30(6.7)$ & 0 & $30(8.8)$ & $<0.001$ \\
\hline $50-59, n(\%)$ & $137(30.4)$ & $14(12.6)$ & $123(36.3)$ & 0.32 \\
\hline $60-69, n(\%)$ & $128(28.5)$ & $30(27.0)$ & $98(28.9)$ & 0.30 \\
\hline $70-79, n(\%)$ & $113(25.1)$ & $44(39.7)$ & $69(20.4)$ & 0.85 \\
\hline$\geq 80, n(\%)$ & $42(9.34)$ & $23(20.7)$ & $19(5.6)$ & 0.83 \\
\hline Body mass, kg & $72.6 \pm 13.9$ & $71.0 \pm 15.1$ & $73.1 \pm 13.6$ & 0.13 \\
\hline Height, cm & $162.7 \pm 6.5$ & $161.3 \pm 7$ & $163.2 \pm 6.27$ & $<0.01$ \\
\hline $\mathrm{BMI}, \mathrm{kg} / \mathrm{m}^{2}$ & $27.4 \pm 4.9$ & $27.2 \pm 5.3$ & $27.5 \pm 4.8$ & 0.68 \\
\hline Overweight, $n(\%)$ & $186(41.3)$ & $48(43.2)$ & $138(40.7)$ & 0.87 \\
\hline Obese, $n(\%)$ & $115(25.6)$ & $25(22.5)$ & $90(26.5)$ & 0.34 \\
\hline \multicolumn{5}{|l|}{ Smokers, $n(\%)$} \\
\hline Past & $113(25.8)$ & $23(20.7)$ & $90(26.6)$ & 0.22 \\
\hline Active & $65(14.5)$ & $7(12.6)$ & $58(17.1)$ & 0.26 \\
\hline Alcohol consumers, $n(\%)$ & $157(34.9)$ & $26(23.4)$ & $131(38.5)$ & $<0.005$ \\
\hline$>3$ units/day & $12(2.67)$ & 0 & $12(3.5)$ & $<0.001$ \\
\hline Menopause (years) & $49.6 \pm 4$ & $49.9 \pm 4.6$ & $49.6 \pm 3.7$ & 0.54 \\
\hline$\leq 45$ years, $n$ & 53 & 13 & 40 & 0.29 \\
\hline Past low-energy fractured, $n(\%)$ & $166(26.89)$ & $70(63.1)$ & $96(28.3)$ & $<0.001$ \\
\hline History of osteoporosis in the family, $n(\%)$ & $104(23.11)$ & $34(30.6)$ & $70(20.7)$ & $<0.05$ \\
\hline Glucocorticoids intake, $n(\%)$ & $51(11.3)$ & $18(16.2)$ & $33(9.7)$ & 0.06 \\
\hline Vitamin D intake, $n(\%)$ & $219(48.66)$ & $78(70.3)$ & $141(41.6)$ & $<0.001$ \\
\hline Dizziness, $n(\%)$ & $185(41.11)$ & $61(54.9)$ & $124(36.6)$ & $<0.001$ \\
\hline Falls during the last year, $n(\%)$ & $188(41.78)$ & $70(63.1)$ & $118(34.8)$ & $<0.001$ \\
\hline Fatigue, $n(\%)$ & $123(27.34)$ & $50(45.0)$ & $73(21.5)$ & $<0.001$ \\
\hline \multicolumn{5}{|l|}{ Co-morbidity, $n$ (\%) } \\
\hline Hypertension & $232(51.5)$ & $63(56.8)$ & $169(49.8)$ & 0.21 \\
\hline Diabetes type 1 & $23(5.1)$ & $5(4.5)$ & $18(5.3)$ & $<0.05$ \\
\hline Diabetes type 2 & $150(33.3)$ & $47(42.3)$ & $103(30.38)$ & $<0.05$ \\
\hline Thyroid diseases & $45(10)$ & $14(12.6)$ & $31(9.1)$ & 0.29 \\
\hline Rheumatoid arthritis & $38(8.4)$ & $10(9.0)$ & $28(8.3)$ & 0.81 \\
\hline Intestinal diseases & $18(4)$ & $7(6.3)$ & $11(3.3)$ & 0.15 \\
\hline Depression & $24(5.34)$ & $9(8.1)$ & $15(4.4)$ & 0.13 \\
\hline
\end{tabular}

\section{Untreated patients}

Only $23 \%$ of patients diagnosed with PMO received optimal treatment (Bisphosphonates + vitamin D + calcium supplementation). While include-women using vitamin D, the proportion of untreated patients with osteoporosis decreased to $22 \%$ (Fig. 2). Notably every fourth $(27 \%)$ of women taking vitamin D though was not being treated for osteoporosis. In addition, $42 \%$ of the group of women without confirmed PMO was taking vitamin D supplementation.
Women with a history of bone fractures and diagnosed with PMO significantly more often had been taking bisphosphonates compared with those without fractures but diagnosed with osteoporosis.

\section{Comparison of FRAX-BMD with FRAX without BMD values}

In this study, we made the decision to start osteoporosis therapy and prevention of MOF taking into ac- 
Table 2. Comparison of women with $(n=166)$ or without history of passed low-energy fractures $(n=284)$

\begin{tabular}{|c|c|c|c|c|}
\hline Characteristics & $\begin{array}{l}\text { All subjects } \\
(n=450)\end{array}$ & $\begin{array}{l}\text { With past low-energy } \\
\text { bone fractured }(n=166)\end{array}$ & $\begin{array}{l}\text { Without past low-energy } \\
\text { bone fractured }(n=284)\end{array}$ & $\begin{array}{c}\text { Statistical } \\
\text { significance }(p)\end{array}$ \\
\hline Age, years & $65.0 \pm 11$ & $69.5 \pm 10.8$ & $62.7 \pm 10.1$ & $<0.001$ \\
\hline$<50, n(\%)$ & $30(6.7)$ & $6(3.6)$ & $24(8.5)$ & 0.05 \\
\hline $50-59, n(\%)$ & $137(30.4)$ & $30(18.1)$ & $107(37.7)$ & $<0.05$ \\
\hline $60-69, n(\%)$ & $128(28.5)$ & $46(27.7)$ & $82(28.7)$ & 0.78 \\
\hline $70-79, n(\%)$ & $113(25.1)$ & $59(35.5)$ & $54(19.0)$ & 0.71 \\
\hline$\geq 80, n(\%)$ & $42(9.34)$ & $25(15.1)$ & $17(6.0)$ & 0.52 \\
\hline Body mass, kg & $72.6 \pm 13.9$ & $70.2 \pm 12.7$ & $74.0 \pm 14.5$ & $<0.005$ \\
\hline Height, cm & $162.7 \pm 6.5$ & $161.7 \pm 6.5$ & $163.4 \pm 6.5$ & $<0.01$ \\
\hline $\mathrm{BMI}, \mathrm{kg} / \mathrm{m}^{2}$ & $27.4 \pm 4.9$ & $26.9 \pm 4.6$ & $27.7 \pm 5.1$ & 0.07 \\
\hline Overweight, $n(\%)$ & $186(41.3)$ & $69(41.6)$ & $117(41.2)$ & 0.63 \\
\hline Obese, $n(\%)$ & $115(25.6)$ & $38(22.9)$ & $77(27.1)$ & 0.15 \\
\hline \multicolumn{5}{|l|}{ Smokers, $n(\%)$} \\
\hline Past & $113(25.78)$ & $43(25.9)$ & $70(24.7)$ & 0.68 \\
\hline Active & $65(14.45)$ & $21(12.6)$ & $44(15.5)$ & 0.67 \\
\hline Alcohol consumers, $n$ (\%) & $157(34.98)$ & $50(30.1)$ & $107(37.6)$ & 0.63 \\
\hline$>3$ units/day & $12(2.67)$ & $4(2.4)$ & $8(2.8)$ & 0.63 \\
\hline Menopausal age (years) & $49.6 \pm 4$ & $50.5 \pm 4.0$ & $49.2 \pm 3.8$ & 0.57 \\
\hline$\leq 45$ years, $n(\%)$ & $53(11.8)$ & $10(6.0)$ & $43(15.1)$ & $<0.001$ \\
\hline $\begin{array}{l}\text { History of osteoporosis in the } \\
\text { family, } n(\%)\end{array}$ & $104(23.11)$ & $54(32.5)$ & $50(17.6)$ & $<0.001$ \\
\hline Glucocorticoids intake, $n$ (\%) & $51(11.3)$ & $29(17.5)$ & $22(7.7)$ & $<0.001$ \\
\hline Vitamin D intake, $n(\%)$ & $219(48.66)$ & $97(58.4)$ & $122(43.0)$ & $<0.001$ \\
\hline Dizziness, $n(\%)$ & $185(41.11)$ & $85(51.2)$ & $100(35.2)$ & $<0.001$ \\
\hline Falls during the last year, $n(\%)$ & $188(41.78)$ & $114(68.7)$ & $74(36.0)$ & $<0.001$ \\
\hline Fatigue, $n(\%)$ & $123(27.34)$ & $61(36.7)$ & $62(21.8)$ & $<0.001$ \\
\hline \multicolumn{5}{|l|}{ Co-morbidity, $n$ (\%) } \\
\hline Hypertension & $232(51.5)$ & $87(52.40)$ & $145(51)$ & 0.78 \\
\hline Diabetes type 1 & $23(5.1)$ & $5(3)$ & $18(6.3)$ & $<0.05$ \\
\hline Diabetes type 2 & $150(33.3)$ & $67(40.3)$ & $83(29.2)$ & $<0.05$ \\
\hline Hyperthyroidism & $45(10)$ & $13(7.8)$ & $32(11.3)$ & 0.24 \\
\hline Rheumatoid arthritis & $38(8.4)$ & $18(10.8)$ & $20(7.0)$ & 0.16 \\
\hline Intestinal diseases & $18(4)$ & $10(6.0)$ & $8(2.8)$ & 0.09 \\
\hline Depression & $24(5.34)$ & $8(4.8)$ & $16(5.6)$ & 0.71 \\
\hline \multicolumn{5}{|l|}{ Osteoporosis } \\
\hline Diagnosed, $n(\%)$ & $111(24.7)$ & $70(42.2)$ & $41(14.4)$ & $<0.001$ \\
\hline Age at diagnosis, years & $62.8 \pm 10.2$ & $64.9 \pm 9.2$ & $60.6 \pm 11.3$ & $<0.05$ \\
\hline Time from diagnosis, years & $7.9 \pm 7$ & $8.6 \pm 7.3$ & $7.1 \pm 6.6$ & 0.14 \\
\hline Therapy, $n(\%)$ & $78(70.2)$ & $52(73.9)$ & $26(63.4)$ & 0.23 \\
\hline Bisphosphonates & $36(46.1)$ & $29(41.4)$ & $7(17)$ & $<0.01$ \\
\hline Calcium supplement & $29(37.2)$ & $15(21.4)$ & $14(34.2)$ & 0.14 \\
\hline Vitamin D & $54(70.2)$ & $41(73.2)$ & $13(36.4)$ & $<0.01$ \\
\hline
\end{tabular}

count FRAX with and without BMD. According to the guidelines therapies of osteoporosis should be introduced at the cut-off point of $10 \%$ FRAX-BMD.

FRAX-BMD $\geq 10 \%$ was found in 64 women, in 46 of them, FRAX without BMD was equal to or greater than 10. Group of 18 women who were "missed" in FRAX without BMD were analyzed for the risk factors of osteoporotic fracture: FRAX risk factors were reported in 10 patients: 5 patients' parents had osteoporosis, 3 had low-energy fractures in the past, 2 were diagnosed 
Table 3. Comparison of BMD and FRAX value for women with T-score $\leq-2.5(n=61)$ and women with T-score $>-2.5(n=52)$

\begin{tabular}{|c|c|c|c|c|}
\hline \multirow[t]{2}{*}{ Characteristic } & \multicolumn{2}{|c|}{ T-score $\leq-2.5$} & \multicolumn{2}{|c|}{ T-score > -2.5} \\
\hline & $\begin{array}{l}\text { With low-energy bone } \\
\text { fractured }(n=30)\end{array}$ & $\begin{array}{l}\text { Without low-energy } \\
\text { bone fractured }(n=31)\end{array}$ & $n=52$ & $\begin{array}{c}\text { Statistical significance } \\
(p)\end{array}$ \\
\hline DXA T-score & $-3.1 \pm 0.4$ & $-2.9 \pm 0.4$ & $-1.8 \pm 0.5$ & \\
\hline FRAX-BMD - MOF (\%) & $24.7 \pm 8.7$ & $13.7 \pm 6.9$ & $7.9 \pm 4.8$ & $<0.001$ \\
\hline FRAX-BMD - HF (\%) & $12.6 \pm 6.1$ & $6.2 \pm 4.0$ & $2.5 \pm 2.5$ & $<0.001$ \\
\hline FRAX without BMD - MOF (\%) & $18.1 \pm 9.6$ & $7.9 \pm 5.7$ & $9.0 \pm 7.6$ & $<0.001$ \\
\hline FRAX without BMD - MOF (\%) & $8.1 \pm 7.7$ & $2.7 \pm 3.2$ & $3.7 \pm 5.6$ & $<0.001$ \\
\hline
\end{tabular}

DXA - dual-energy X-ray absorptiometry, FRAX - fracture risk assessment tool, BMD - bone mineral density, MOF - major osteoporotic fractures, HF - hip fractures

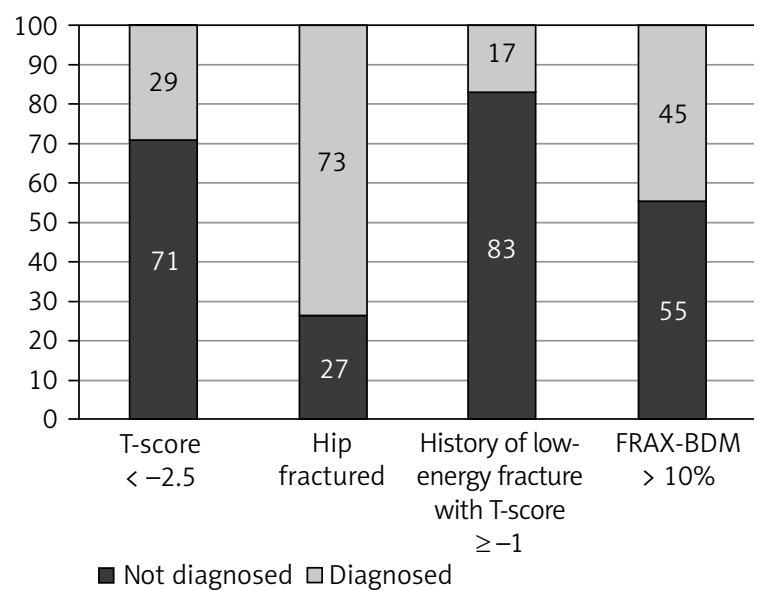

Fig. 1. Undiagnosed osteoporosis in postmenopausal women $(n=103)$

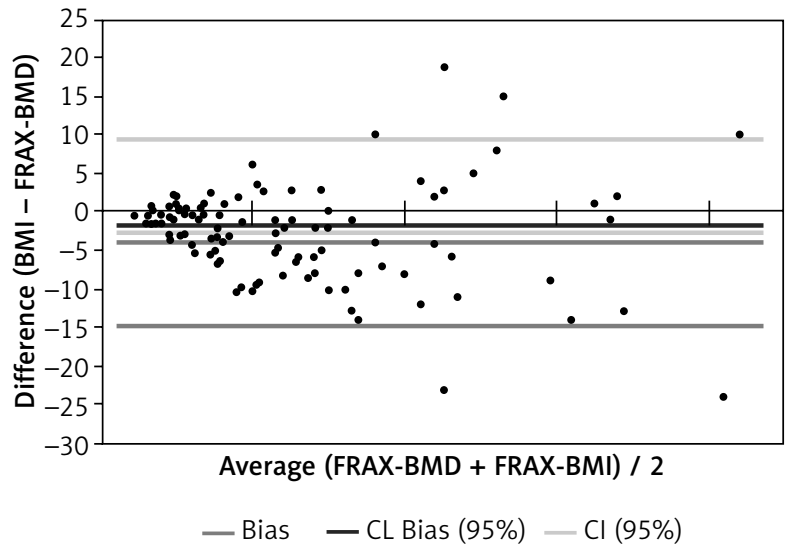

Fig. 3. The comparison of FRAX-BMD and FRAX-BMI (BlandAltman method)

with RA. Eight women (12.5\%) would not be considered for further diagnosis/prevention if the assessment was based only on the FRAX calculator without knowing the result of the densitometry (Fig. 3).

\section{Discussion}

Approximately $30 \%$ of all postmenopausal women in the United States [18], 21\% in Europe [2], 20\% in

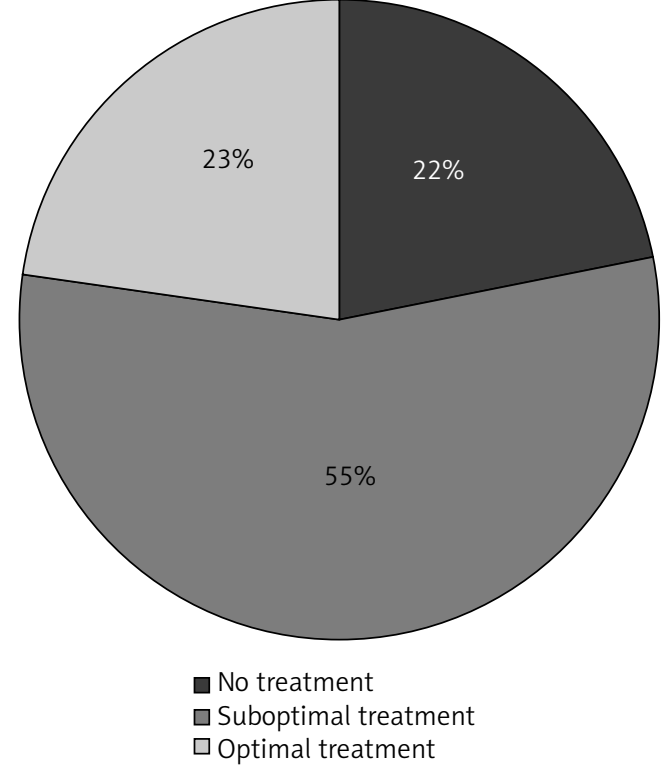

Fig. 2. Optimal and suboptimal treatment for osteoporosis among patients with the disease $(n=111)$

Poland [19] and $15.1 \%$ in Iran [20] suffer from osteoporosis. Similarly, results of our study show that $23.7 \%$ postmenopausal women visiting primary health care centers (GP's), internal medicine wards and densitometry centers localized in the Upper Silesia region, suffers from osteoporosis, and meets the criteria of having already known risk factors of fractures such as older age, family history of osteoporosis, use of the glucocorticoids [3, 4, 15, 21] and chronic fatigue [22].

Of note $59 \%$ of the patients that fulfilled the clinical criteria of osteoporosis or in densitometry had not been previously diagnosed with osteoporosis. The number is lower than showed by Major et al. $-71.5 \%$ in female patients of the geriatric post-acute rehabilitation unit in Switzerland [13]. In contrary Gillespie and Morin showed much lower rate $15 \%$ of previously recognized osteoporosis in patients after first HF [12]. These discrepancies are too large to be explained by differences in the methods of patient recruitment, history of fractures and age. It should be emphasized that 24 and $18 \%$ undiagnosed patients were managed by orthopedist and rheumatol- 
ogists. The highest percentage (83\%) of undiagnosed patients were among those with prior low energy fractures and osteopenia in densitometry examination. It is a worldwide problem, GPs do not know about FRAX calculator or they declare that have no time to use it [23] .

Densitometry examination of femoral neck is a gold standard of the diagnosis of osteoporosis; however, it is impossible and not cost-effective to recommend it for all postmenopausal women. Therefore, various questionnaires including risk factors, have been developed to help physicians to identify patients with high risk of osteoporosis. There are numerous calculators around the world, e.g. Qfracture, Garvan Fracture Risk Calculator, Canadian Risk for Osteoporosis Calculator (CAROC), the Simple Calculated Osteoporosis Risk Index (SCORE), the Osteoporosis Risk Assessment Index (ORAI), the Osteoporotic Self-assessment Tool (OST), ABONE, but the most useful and the most extensive is the WHO FRAX [24]. FRAX is an algorithm that assess the 10-year probability of a MOF and the 10-year probability of HF. Fracture risk is calculated from anthropometric data and validated risk factors. Femoral neck BMD could be optionally used. Probability of osteoporosis fracture differs in various countries so that FRAX is calibrated for those countries where the epidemiology of fracture is known. For Polish population a special version of FRAX calculator was created $[25,26]$. Our results of FRAX with and without BMD for MOF and HF were compared in two similar studies in Poland. One of them was conducted by Badurski et al. They examined group of 1608 women at the age of 40-89 [27]. The second one examined 1014 patients at the age of 50-89 and was performed by Strugata et al. [21] We showed the results for 10-year probability of MOF taking into account the value of BMD was $14 \%$, the 10 -year probability of $\mathrm{HF}$ was $6.2 \%$. For FRAX without BMD it was: $11.1 \%$ and $4.6 \%$ respectively. Badurski et al. [27] and Strugała et al. [21] had similar results of risk for 10-years risk of MOF. However, they noticed lower risk of HF with known BMD value (3,1\% and $3.2 \%$ vs. our $6.2 \%)$. Also Badurski et al. [27] observed lower value of FRAX without BMD for HF (2.8\% vs. $4.6 \%)$. The differences between the results can be caused by the fact that Badurski et al. [27] used FRAX calculator for English population, and the examined group was younger, obviously exposed to lower risk [28]. In our real-life cohort, the risk of fracture grows by $3.2 \%$ for FRAX-BMD and up to $6.6 \%$ for FRAX without BMD. For Polish postmenopausal women population at Upper Silesia area, 5 years risk of fractures assessment calculator was developed, but the study to create useful 10 year risk estimation tool is still ongoing. The results that would be obtained in the future could be compared with the results of our study because both groups come from Upper Silesia and the groups are at similar age [29]. 10\% FRAX-BMD is a cutoff point value from which the guidelines for Polish patients recommends the implementation the therapy for osteoporosis [26]. In our study we compared values of FRAX with and without BMD. FRAX-BMD $\geq 10 \%$ was found in 64 women, and in $72 \%$ the risk was similar using FRAX without BMD. Ten of 18 women who had been "missed" in FRAX without BMD had however risk factors of osteoporotic fractures. This suggest that patient with FRAX without BMD slightly below $10 \%$ may most benefit from referral to densitometry.

In should be pointed out that the diagnosis of PMO is not the only reason to start antiosteoporotic therapy. Even though the PMO diagnosis is established, a great percentage of patients not receiving treatment, especially an optimal one. $23 \%$ of patients in our survey were treated according to recommendations and next $55 \%$ received incomplete therapy, for example only with vitamin D supplements, advertised by Polish multimedia for last few years. As compared to USA $30.4 \%$ of patients received an optimal treatment [14]. According to the report prepared in the collaboration with International Osteoporosis Foundation (IOF) and the European Federation of Pharmaceutical Industry Associations (EFPIA) - $43 \%$ women in the EU and $27 \%$ in Poland, suffering from osteoporosis are receiving treatment [15]. As mentioned before it is caused by low adherence-related to an asymptomatic course of osteoporosis, delayed effects of the treatment, complicated schedule of oral bisphosphonates administration, and polypharmacy related to comorbidities of older women experiencing low energetic fractures [17].

We would like to emphasize that the one of study limitations could be the recruitment method of patients, that might cause over-representation of patients with risk of fracture who receiving medical services more often. So, the recognition and implementation of treatment for osteoporosis could be better.

The results might vary from other regions of Poland due to differences in lifestyle, employment, diet, leisure time habits and environment of Upper Silesian Region.

\section{Conclusions}

In summary, osteoporosis often remains undiagnosed and untreated in the population of postmenopausal women. There is a great need to encourage physicians, especially GPs for using FRAX without BMD calculator, as reliable data source for the start of treatment. Women with burden of risk factors of fractures (i.e. familial osteoporosis, RA or glucocorticoid therapy) and borderline FRAX without BMD values, should be referred to a densitometry examination, as having greater risk of fracture than shown by FRAX without BMD.

\section{Disclosure}

The authors report no conflict of interest. 


\section{References}

1. NIH Consensus Development Panel on Osteoporosis Prevention, Diagnosis, and Therapy. Osteoporosis Prevention, Diagnosis, and Therapy. JAMA 2001; 285: 785-795.

2. Kanis JA, Cooper C, Rizzoli R, Reginster JY; Scientific Advisory Board of the European Society for Clinical and Economic Aspects of Osteoporosis (ESCEO) and the Committees of Scientific Advisors and National Societies of the International Osteoporosis Foundation (IOF). European guidance for the diagnosis and management of osteoporosis in postmenopausal women. Osteoporos Int 2019; 30: 3-44.

3. Janiszewska M, Kulik T, Dziedzic M, et al. Osteoporoza jako problem społeczny - patogeneza, objawy i czynniki ryzyka osteoporozy pomenopauzalnej. Probl Hig Epidemiol 2015; 96: 106-114.

4. Cummings SR, Melton LJ. Epidemiology and outcomes of osteoporotic fractures. Lancet 2002; 359: 1761-1767.

5. Abrahamsen B, van Staa T, Ariely R, et al. Excess mortality following hip fracture: a systematic epidemiological review. Osteoporos Int 2009; 20 1633-1650.

6. Office of the Surgeon General (US). Bone Health and Osteoporosis: A Report of the Surgeon General. Rockville (MD) 2004.

7. World Health Organization. Assessment of fracture risk and its application to screening for postmenopausal osteoporosis. Technical Report Series, vol. 843. WHO, Geneva 1994.

8. Siris ES, Adler R, Bilezikian J, et al. The clinical diagnosis of osteoporosis: a position statement from the National Bone Health Alliance Working Group. Osteoporos Int 2014; 25: 1439-1443.

9. Czerwiński E, Osieleniec J, Berwecka M. Expanded criteria for diagnosis of osteoporosis. Post N Med 2016; 29: 767-769.

10. Kanis JA, Hans D, Cooper C, et al. Interpretation and use of FRAX in clinical practice. Osteoporos Int 2011; 22: 2395-2411.

11. Zaheer S, LeBoff MS. Osteoporosis: Prevention and Treatment. Endotext [Internet]. Feingold KR, Anawalt B, Boyce A, et al. (eds.). MDText.com, Inc. South Dartmouth (MA): 2000.

12. Gillespie CW, Morin PE. Osteoporosis-Related Health Services Utilization Following First Hip Fracture Among a Cohort of Privately-Insured Women in the United States, 2008-2014: An Observational Study. J Bone Miner Res 2017; 32: 1052-1061.

13. Major K, Monod S, Bula CJ, et al. Unknown osteoporosis in older patients admitted to post-acute rehabilitation [published online ahead of print, 2019 Aug 28]. Aging Clin Exp Res 2019; 32: 1145-1152.

14. Yusuf AA, Matlon TJ, Grauer A, et al. Utilization of osteoporosis medication after a fragility fracture among elderly Medicare beneficiaries. Arch Osteoporos 2016; 11: 31.

15. Hernlund E, Svedbom A, Ivergård M, et al. Osteoporosis in the European Union: medical management, epidemiology and economic burden. A report prepared in collaboration with the International Osteoporosis Foundation (IOF) and the European Federation of Pharmaceutical Industry Associations (EFPIA). Arch Osteoporos 2013; 8: 136.

16. Svedbom A, Hernlund E, Ivergård $M$, et al. Osteoporosis in the European Union: a compendium of country-specific reports. Arch Osteoporos 2013; 8: 137.

17. Marcinowska-Suchowierska E, Głuszko P, Badurski J, et al. Leczenie farmakologiczne osteoporozy w Polsce - dostępność, przyczyny braku jej wdrażania. Post Nauk Med 2015; 12: 879-885.

18. Melton LJ, Chrischilles EA, Cooper C, et al. Perspective. How many women have osteoporosis? J Bone Miner Res 1992; 7: 1005-1010.

19. Bączyk G, Opala T, Bartosik W. Funkcjonowanie i jakość życia kobiet z osteoporozą w okresie pomenopauzalnym. Ortop Traumatol Rehabi 2007; 9: 152-154

20. Behzadvand A, Abbaspoor Z, Malehi AS, Javadnoori M. Relationship between reproductive factors and bone mineral density in postmenopausal women. Fam Med Primary Care Rev 2019; 21: 209-213.

21. Strugała C, Sobala W, Szubert Z, Hanke W. Ocena ryzyka złamań osteoporotycznych w populacji kobiet w wieku powyżej 50 lat - analiza wskaźników FRAX® BMI i FRAX® BMD. Med Pr 2013; 64: 327-333.

22. Chen CS, Lin WM, Yang TY, et al. Chronic fatigue syndrome is associated with the risk of fracture: a nationwide cohort study. QJM 2014; 107: 635-641.
23. Bruyere O, Nicolet D, Compere S, et al. Perception, knowledge, and use by general practitioners of Belgium of a new WHO tool (FRAX) to assess the 10-year probability of fracture. Rheumatol Int 2013; 33: 979-983.

24. Edwards BJ. Osteoporosis Risk Calculators. J Clin Densitom 2017; 20: 379-388.

25. Kanis JA, Johansson H, Harvey NC, McCloskey EV. A brief history of FRAX. Arch Osteoporos 2018; 13: 118.

26. Kanis JA, Harvey NC, Cooper C, et al. A systematic review of intervention thresholds based on FRAX: A report prepared for the National Osteoporosis Guideline Group and the International Osteoporosis Foundation. Arch Osteoporos 2016; 11: 25.

27. Badurski JE, Dobreńko A, Nowak N, et al. Epidemiologia złamań osteoporotycznych i ocena 10-letniego ryzyka złamania w populacji kobiet regionu Białystok (BOS-2) algorytmem FRAX - WHO. Reumatologia 2008; 2: 72-79.

28. Andrade SE, Majumdar SR, Chan KA, et al. Low frequency of treatment of osteoporosis among postmenopausal women following a fracture. Arch Intern Med 2003; 163: 2052-2057.

29. Adamczyk P, Werner A, Bach M, et al. Risk Factors for Fractures Identified in the Algorithm Developed in 5-Year Follow-Up of Postmenopausal Women From RACOST-POLStudy. J Clin Densitom 2018; 21: 213-219. 